\title{
AMINASI HYPERBRANCHED POLYGLYCEROL (HPG) DENGAN GAS AMONIA
}

\author{
Dwinna Rahmi \\ Balai Besar Kimia dan Kemasan, \\ Jl. Balai Kimia No. 1 Pekayon Pasar Rebo, Jakarta 13069. Indonesia \\ E-mail: dwinna2002@yahoo.com \\ Received : 21 Maret 2018; revised : 11 April 2018; accepted : 12 April 2018
}

\begin{abstract}
ABSTRAK
AMINASI HYPERBRANCHED POLYGLYCEROL (HPG) DENGAN GAS AMONIA. Hyperbranched polyglycerol amine (HPG-amina) adalah salah satu senyawa amin yang berpotensi diterapkan pada berbagai industri. Saat ini HPG-amina disintesis dari proses aminasi HPG dengan diethylamine melalui reaksi tosilasi. Metoda ini sulit bila ditingkatkan menjadi skala industri dan juga kurang ramah lingkungan. Penelitian ini bertujuan melakukan proses aminasi dengan menggunakan gas amonia dalam reaktor tertutup. Penambahan katalis logam $\mathrm{Fe}$ dan $\mathrm{Ni}$, suhu reaksi dan waktu proses berpengaruh signifikan terhadap produk yang dihasilkan. Dari hasil uji gugus fungsi HPG-amina yang diproses dengan penambahan katalis Ni pada suhu $100{ }^{\circ} \mathrm{C}$ selama 8 jam menunjukkan adanya kandungan amina primer $-\mathrm{CONH}_{2}$ dan amina sekunder $\mathrm{R}-\mathrm{NH}$ dengan kandungan $\mathrm{N}$ total sebesar 6,7 ppm dan amonia bebas sebesar 3,4 ppm. Aminasi yang dilakukan tanpa penambahan katalis dan penambahan katalis Fe menghasilkan HPG-amina dengan sedikit gugus $\mathrm{R}-\mathrm{NH}$ dan $\mathrm{C}=\mathrm{O}$ yang belum bereaksi dengan amonia. Suhu proses di atas $100{ }^{\circ} \mathrm{C}$ menjadikan HPG-amina berwarna lebih gelap dan bahkan terlihat keruh. Proses yang dilakukan lebih dari 8 jam menurunkan kandungan $\mathrm{N}$ total menjadi 5,8 ppm.
\end{abstract}

Kata Kunci : Amina, HPG-amina, Gas amonia

\section{ABSTRACT}

AMINATION OF HYPERBRANCHED POL YGL YCEROL USING AMMONIA GAS. Hyperbranched polyglycerol amine (HPG-amine) is one of the potential amine compounds for application in various industries. Recently, the reaction of HPG-amine by using diethylamine through tosylation has been synthesized. However, this method is difficult to be upgraded to industrial scale and also less environmentally friendly. The purpose of this research is to apply amination process by using ammonia gas in the closed reactor. The addition of catalysts such as Fe and $\mathrm{Ni}$, reaction temperature and time of the process have a significant effect on the product. The analysis of HPGamine functional group processed by addition of Ni catalyst at temperature $100{ }^{\circ} \mathrm{C}$ for 8 hours showed the presence of primary amine-CONH2 and secondary amine R-NH with N content of $6.7 \mathrm{ppm}$ and $3.4 \mathrm{ppm}$ of free ammonia. On the contrary, the amination process without the addition of catalyst and with the addition of $\mathrm{Fe}$ catalyst showed small peaks of $\mathrm{R}-\mathrm{HH}$ and $\mathrm{C}=\mathrm{O}$, which was not reacted with the ammonia. The temperature at $160{ }^{\circ} \mathrm{C}-290{ }^{\circ} \mathrm{C}$ produced darker and cloudy HPG-amine. The process performed over 8 hours reduced the total $N$ content to 5.8 ppm.

Keywords: Amine, HPG-amine, Ammonia gas

\section{PENDAHULUAN}

Produk amina merupakan bahan yang penting untuk industri kimia maupun proses biologi. Diantara produk amina yang sudah diproduksi di industri, alkohol amina merupakan produk yang paling banyak diproduksi saat ini (Bähn et al. 2011).

Hyperbranced polyglycerol (HPG) merupakan alkohol dengan rantai panjang dan bercabang. HPG adalah salah satu jenis Hyperbranced Polymer (HP) dengan struktur perpanjangan rantai dari gliserol. HP dikenal juga dengan polimer banyak cabang yang termasuk makromolekul di mana berpotensi diaplikasikan pada berbagai bidang. HP yang kaya akan gugus fungsi dipakai sebagai bahan tambahan (aditif), pelapis (coating), nanoreaktor, drug delivery, katalis, sensor dan sebagainya (Gao dan Yan 2004). Industri yang sudah menggunakan HP di antaranya industri tekstil, plastik, membran, pelumas, personal care dan sebagainya (Seiler 2006). Dalam penggunaannya gugus fungsi pada $H P$ dapat dimodifikasi untuk menyesuaikan dengan kebutuhan industri (Hajji dan Haag 2006), salah 
satunya dengan amina. Beberapa $H P$ yang dimodifikasi dengan amina sudah tersedia secara komersial seperti polysulfoneamine (HPSA), polyesteramine (HPAEs), polyamidoaine (PAMAM) (Gao dan Yan 2004).

$H P G$ dengan gugus fungsi amina juga sudah diaplikasikan pada proses katalisis (Salazar, Fomina, dan Fomine 2001) (Salazar, Fomina, dan Fomine 2001), pengantar obat (drug delivery) (Hellmund et al. 2015) dan sebagainya. Selain itu, HPG dapat menggantikan fungsi PAMAM yang lebih beracun karena muatan ion positifnya yang tinggi (Hellmund et al. 2015). Proses aminasi pada pembuatan HPG-amine yang umum dipakai adalah melalui tosilasi. HPG yang kaya gugus hidroksil membentuk gugus amina dari reaksi dengan dietilamin melalui reaksi tosilasi (Salazar, Fomina, dan Fomine 2001). Reaksi tosilasi dengan larutan diethylamine membutuhkan waktu dan tahapan yang panjang dengan pengamatan yang butuh kehati-hatian (Rahmi, Yunilawati, dan Riyanto 2016) sehingga sulit apabila diproduksi skala industri. Selain itu penggunaan dietilamin kurang ramah lingkungan.

Amonia adalah bahan amin yang umum dipakai untuk proses aminasi pada industri. Penggunaan gas amonia pada proses aminasi di industri sudah dilakukan sejak awal abad 20 (Bähn et al. 2011). Gas amonia selain lebih sesuai untuk skala industri juga ramah lingkungan. Hal ini karena penggunaan amonia sebagai pereaksi hanya menghasilkan air sebagai produk samping. Oleh karena itu, pada penelitian ini proses aminasi dilakukan dengan menggunakan gas amonia dan dilakukan dalam reaktor tertutup. Metoda ini nantinya dapat memberi data ke industri dan mempermudah dalam memperbesar produksi menjadi skala industri. Tujuan dari penelitian ini adalah mereaksikan HPG dengan gas amonia untuk menghasilkan HPG-amina.

\section{BAHAN DAN METODE}

\section{Bahan dan Alat}

Bahan utama adalah gliserol yang diperoleh dari PT. Wilmar Gersik Jawa Timur. Gas nitrogen dan gas amonia diperoleh dari PT. Windu. Katalis Ni pricat 9902 dari Johnson Matthey dan katalis $\mathrm{Fe}$ disiapkan dari $\mathrm{FeSO}_{4}$. $7 \mathrm{H}_{2} \mathrm{O}$ dari Merck yang dikalsinasi pada suhu $400{ }^{\circ} \mathrm{C}$.

Peralatan yang digunakan adalah reaktor tertutup merek PARR kapasitas $1 \mathrm{~L}$ yang dilengkapi dengan pemanas, pendingin, aliran pipa gas dan pengaduk.

\section{Metode}

HPG disiapkan dengan cara polimerisasi gliserol dengan penambahan katalis kapur tohor (Rahmi, Yunilawati, dan Riyanto 2016). Selanjutnya proses aminasi HPG dilakukan dengan mereaksikan HPG dengan gas amonia dengan penambahan katalis $\mathrm{Fe}$ dan $\mathrm{Ni}$. Pemilihan katalis $\mathrm{Fe}$ dan Ni dikarenakan katalis ini lebih mudah didapat dan lebih ekonomis walaupun katalis dari logam tanah jarang diketahui lebih aktif pada proses aminasi alkohol (Hollmann 2008).

Sebanyak 500 g HPG ditambah katalis $1 \%$ lalu dimasukkan ke dalam wadah reaktor. Selanjutnya reaktor ditutup dan purging dengan gas nitrogen selama 10 menit. Gas amonia dialirkan ke dalam reaktor sambil diaduk dengan kecepatan $100 \mathrm{rpm}$. Panaskan reaktor pada suhu tertentu $\left(100{ }^{\circ} \mathrm{C}, 160{ }^{\circ} \mathrm{C}, 290{ }^{\circ} \mathrm{C}\right)$ selama 20 jam.

Untuk mengetahui gugus fungsi maka dilakukan uji dengan Fourier Transform Infrared Spectroscopy (FTIR). Analisis N total dilakukan dengan cara Kjeldahl yang umum dipakai untuk analisis sampel yang mengandung nitrogen, sedangkan analisis kandungan amina dengan mendidihkan sampel terlebih dahulu untuk menghilangkan amonia bebas kemudian dititrasi dengan $\mathrm{HCl}$. Total amina dihitung dengan cara mengalikan volume $\mathrm{HCl}$ dengan konsentrasi $\mathrm{HCl}$ dan berat molekul amina lalu dibagi berat sampel.

\section{HASIL DAN PEMBAHASAN}

Proses aminasi dibagi dua yaitu aminasi secara reduksi dan aminasi dengan menggunakan amonia. Aminasi secara reduksi dilakukan pada senyawa yang sudah mengandung gugus amina (Santoro et al. 2012) sedangkan proses aminasi dengan amonia yang dikenal dengan amonolisis (Griffin, Atherton, dan Page 2013). Amonolisis adalah proses aminasi senyawa lain seperti alkohol, eter dan keton dengan amonia. Pada penelitian ini poligliserol yang merupakan poliol di amonolisis dengan menggunakan gas amonia.

Berbeda dengan aminasi alkohol lainnya, produk samping air pada aminasi poligliserol tidak banyak. Ini karena pada proses polimerisasi gliserol menjadi HPG, air yang sudah terpisah dan sebagian menguap (Rahmi et al. 2017). Sama seperti proses kimia umumnya, proses aminasi dipengaruhi oleh katalis, suhu dan waktu (Likhar et al. 2009). llustrasi mekanisme reaksi HPG dengan gas amonia dapat dilihat pada Gambar 1. 


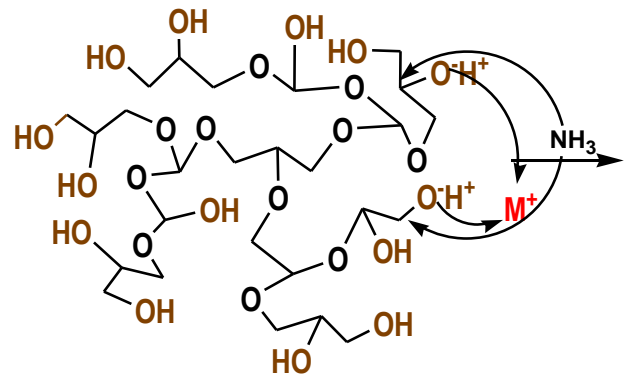

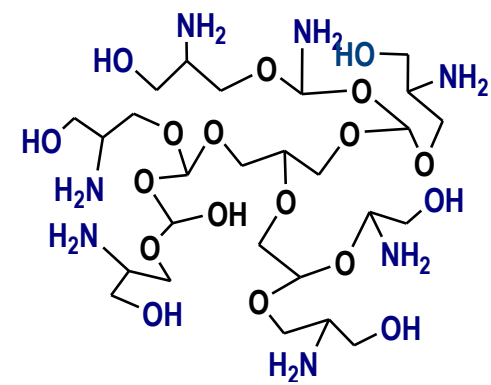

Gambar 1. Ilustrasi mekanisme reaksi aminasi HPG dengan gas amonia (Bähn et al. 2011)

Pada Gambar 1 terlihat katalis logam (M) yang kaya akan muatan positif menarik gugus hidroksi $(\mathrm{OH})$, selanjutnya gugus $\mathrm{C}$ pada $H P G$ yang kaya muatan positif mengikat gas amonia yang dialirkan ke dalam reaktor yang berisi poligliserol.

\section{Pengaruh jenis katalis terhadap gugus amina}

Pada penelitian ini katalis yang digunakan adalah katalis logam yaitu $\mathrm{Fe}$ dan Ni. Proses dilakukan pada suhu $240{ }^{\circ} \mathrm{C}$, waktu 20 jam dan kecepatan pengadukan $100 \mathrm{rpm}$. Produk HPGamine yang dihasilkan berwarna coklat tua dan selanjutnya diuji gugus fungsi dengan FTIR. Gambar 2 memperlihatkan spektrum dari produk HPG-amina tanpa katalis, dengan katalis Fe dan dengan katalis $\mathrm{Ni}$. Katalis logam banyak digunakan dalam proses aminasi alkohol dengan amonia. Katalis logam yang umum dipakai adalah krom (Cr), nikel (Ni), kobal (Co), besi (Fe) dan tembaga (Cu) (Bähn et al. 2011).

Pada Gambar 2 ada beberapa gugus yang menandakan adanya gugus poliol yaitu gugus hidroksi $(\mathrm{O}-\mathrm{H})$ pada panjang gelombang $3200 \mathrm{~cm}^{-1}-3500 \mathrm{~cm}^{-1}$; gugus alkana $(\mathrm{C}-\mathrm{H})$ pada panjang gelombang $2960 \mathrm{~cm}^{-1}-2850 \mathrm{~cm}^{-1}$; dan gugus $\mathrm{C}-\mathrm{O}$ pada panjang gelombang $1000 \mathrm{~cm}^{-1}$ - $1250 \mathrm{~cm}^{-1}$. Puncak-puncak ini terlihat pada ketiga spektrum yaitu pada produk yang diproses tanpa katalis, katalis $\mathrm{Fe}$ dan katalis $\mathrm{Ni}$. Perbedaan terlihat pada puncak yang muncul pada panjang gelombang $1592 \mathrm{~cm}^{-1}$ dan 1667 $\mathrm{cm}^{-1}$. Gugus fungsi pada pajang gelombang $1580 \mathrm{~cm}^{-1}-1660 \mathrm{~cm}^{-1}$ diindikasikan sebagai amina sekunder $\mathrm{R}-\mathrm{NH}$ dan gugus fungsi pada panjang gelombang $1650 \mathrm{~cm}^{-1}-1690 \mathrm{~cm}^{-1}$ adalah sebagai amina primer - $\mathrm{CONH}_{2}$ (Khatri et al. 2006). Pada Gambar 2 terlihat adanya tiga puncak pada panjang gelombang $1592 \mathrm{~cm}^{-1}$ yang diindikasikan sebagai $\mathrm{R}-\mathrm{NH}$; pada panjang gelombang $1667 \mathrm{~cm}^{-1}$ yang diindikasikan sebagai - $\mathrm{CONH}_{2}$; dan panjang gelombang 1750 $\mathrm{cm}^{-1}$ yang mengindikasikan sebagai $\mathrm{C}=\mathrm{O}$.

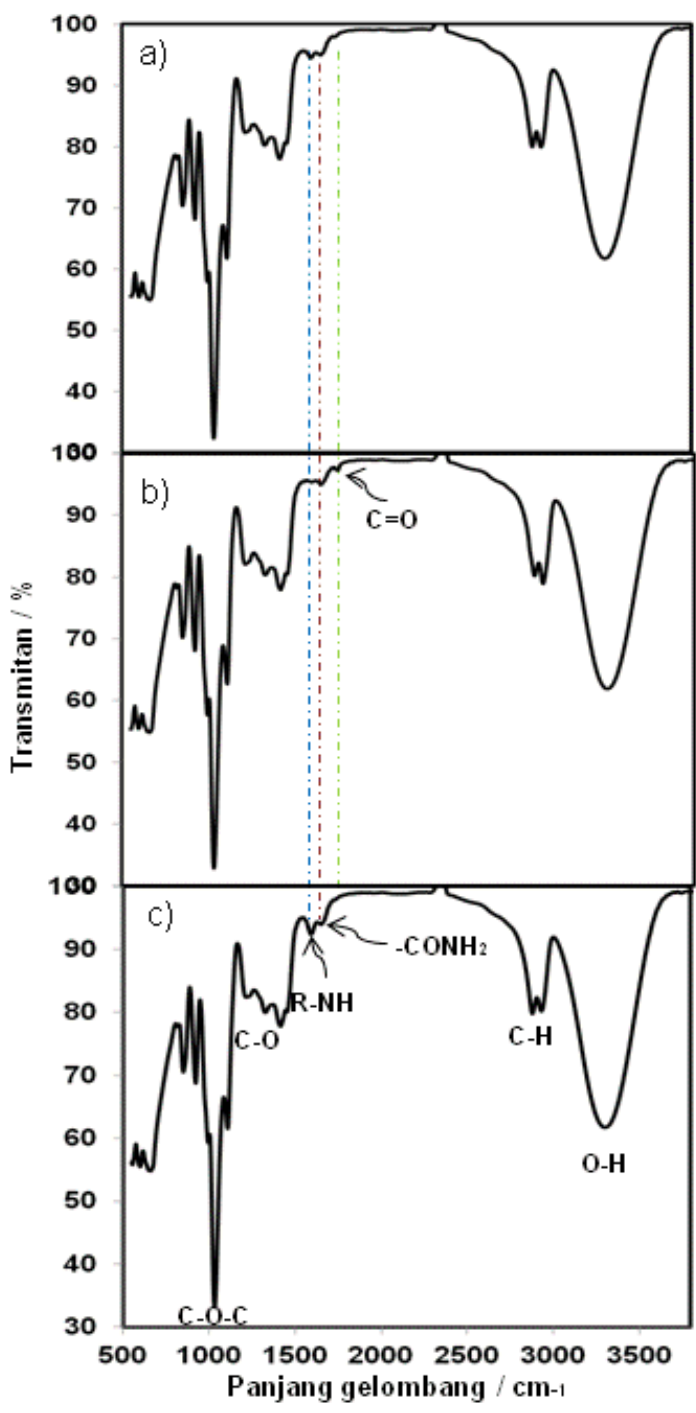

Gambar 2. Spektrum FTIR produk HPG-amina dengan proses: (a) tanpa katalis, (b) katalis $\mathrm{Fe}$, (c) katalis $\mathrm{Ni}$. 
Gugus amina pada Gambar 2a yaitu aminasi tanpa katalis terlihat dua puncak kecil yang terindikasi sebagai $\mathrm{R}-\mathrm{NH}$ dan $\mathrm{C}=\mathrm{O}$.

Penggunaan katalis $\mathrm{Fe}$ sudah dilakukan oleh Pan, Ng, dan Zhao (2015) pada reaksi alkohol melalui asam lewis. Pada Gambar 2b, HPG-amina yang diproses dengan bantuan katalis $\mathrm{Fe}$ terlihat dua puncak yang menonjol yaitu gugus karbonil $\mathrm{C}=\mathrm{O}$ dan amina primer $\mathrm{CONH}_{2}$. Aminasi alkohol dengan penambahan katalis logam dimulai dengan oksidasi alkohol menjadi senyawa karbonil, lalu mereduksi imina menjadi senyawa amina (Likhar et al. 2009).

Proses aminasi aldehid dan alkohol dengan penambahan katalis $\mathrm{Ni}$ sudah dilakukan oleh Gomez, Peters, dan Maschmeyer (2002). Gambar 2c yaitu produk dengan proses aminasi menggunakan katalis $\mathrm{Ni}$ terlihat dua puncak pada panjang gelombang $1592 \mathrm{~cm}^{-1}$ yaitu amina sekunder R-NH dan amina primer - $\mathrm{CONH}_{2}$. Dari hasil di atas diketahui bahwa dengan bantuan katalis reaksi aminasi dengan gas amonia dapat terjadi. Katalis $\mathrm{Ni}$ lebih reaktif dibandingkan dengan katalis $\mathrm{Fe}$. Ini terlihat dari gugus amina yang terbentuk.

\section{Pengaruh suhu terhadap kandungan amina}

Suhu juga diketahui dapat mepercepat reaksi. Akan tetapi suhu juga mempengaruhi penampakan produk akhir yang dihasilkan. Hal ini juga dipengaruhi oleh sifat dan karakteristik dari bahan yang diaminasi. Menurut Bähn et al. (2011) reaksi aminasi metanol dan amonia membutuhkan suhu tinggi $300{ }^{\circ} \mathrm{C}-500{ }^{\circ} \mathrm{C}$, sedangkan Likhar et al. (2009) mereaksikan alkohol rantai panjang dengan amonia pada suhu $160{ }^{\circ} \mathrm{C}$. Pada penelitian ini dilakukan proses aminasi dengan penambahan katalis $\mathrm{Ni}$ dalam $H P G$ yang diproses pada suhu yang ditentukan yaitu $100{ }^{\circ} \mathrm{C}, 160{ }^{\circ} \mathrm{C}$ dan $290{ }^{\circ} \mathrm{C}$ selama 20 jam. Pemilihan suhu ini berdasarkan kepada titik didih gliserol yaitu $290{ }^{\circ} \mathrm{C}, H P G-$ amina $160{ }^{\circ} \mathrm{C}$ dan dibawah titik didih HPGamina. Hasil dapat dilihat pada Tabel 1 yaitu hasil pengamatan fisik pada warna dan penampakan dari produk HPG-amina yang dihasilkan. Produk HPG-amina yang diproses pada suhu $100{ }^{\circ} \mathrm{C}$ dan $160^{\circ} \mathrm{C}$ berwarna kuning jernih sedangkan yang diproses pada suhu $290{ }^{\circ} \mathrm{C}$ menghasilkan HPG-amina berwarna coklat tua keruh. Hal ini kemungkinan berhubungan dengan titik didih bahan. Ketika gliserol diproses pada suhu $250{ }^{\circ} \mathrm{C}$ menghasilkan produk berwarna kuning muda bening, ini karena titik didih gliserol pada $290{ }^{\circ} \mathrm{C}$ (Rahmi, Yunilawati, dan Riyanto 2016). Dari uji titik didih diketahui titik didih $H P G$ adalah $160^{\circ} \mathrm{C}$, sehingga pemanasan di atas titik didih menjadikan produk terlihat gosong. Selain itu, proses aminasi kondisi tidak vakum karena selama proses gas amonia dialirkan menyebabkan kemungkinan adanya udara masuk.

Selanjutnya untuk HPG-amina yang jernih, yaitu HPG-amina yang diproses pada suhu $100{ }^{\circ} \mathrm{C}$ dan $160{ }^{\circ} \mathrm{C}$, dilakukan uji gugus fungsi dengan FTIR. Terlihat pada Gambar 3 adanya perbedaan puncak yang keluar pada panjang gelombang yang berbeda. Gambar 3a adalah HPG-amina yang diproses pada suhu $160{ }^{\circ} \mathrm{C}$, menghasilkan gugus amina sekunder R$\mathrm{NH}$ dan karboksil $\mathrm{C}=\mathrm{O}$. Amina sekunder terjadi karena proses aminasi masih berlanjut yang merubah amina primer menjadi amina sekunder. Produk ini juga masih menyisakan gugus karboksil yang belum bereaksi dengan amonia untuk menghasilkan gugus amonia. Gambar 3b yaitu proses aminasi pada suhu $100{ }^{\circ} \mathrm{C}$ terlihat adanya gugus amina primer $-\mathrm{CONH}_{2}$.

Tabel 1. Warna dan penampakan produk HPG-amina

\begin{tabular}{cccc}
\hline No & Suhu $/{ }^{\circ} \mathrm{C}$ & Warna & Penampakan \\
\hline 1 & 100 & $\begin{array}{c}\text { Kuning } \\
\text { muda } \\
\text { Kuning tua }\end{array}$ & Jernih \\
2 & 160 & Jernih \\
3 & 290 & Coklat tua & Keruh \\
\hline
\end{tabular}

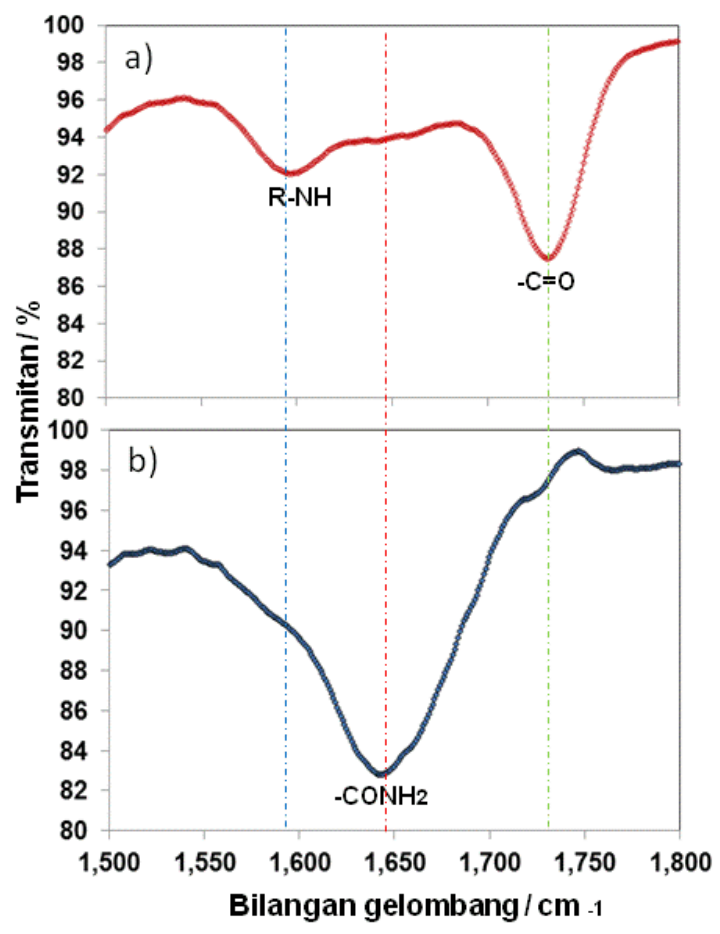

Gambar 3. Spektrum FTIR produk amina dengan katalis Ni pada (a) suhu $160{ }^{\circ} \mathrm{C}$, (b) suhu $100{ }^{\circ} \mathrm{C}$. 


\section{Pengaruh lama proses terhadap kandungan amina}

Waktu proses merupakan salah satu faktor yang menentukan kecepatan dan ketepatan suatu reaksi aminasi (Bähn et al. 2011). Santoro et al. (2012) melakukan reaksi aminasi alkohol dengan variabel waktu selama 2 jam - 24 jam dengan katalis $\mathrm{Cu}$, didapat bahwa 6 jam merupakan waktu yang optimal. Gomez et al. (2002) melakukan proses aminasi dengan katalis Ni selama 4 jam -6 jam.

Pada penelitian ini, selain jenis katalis dan suhu proses, waktu proses juga menentukan produk HPG-amina yang dihasilkan. Untuk mengetahui pengaruh waktu dilakukan proses selama 6 jam, 8 jam dan 20 jam, pada suhu $100{ }^{\circ} \mathrm{C}$ dengan katalis Ni. Kandungan amina yang terkandung dalam HPG-amina diprediksi dengan menguji kandungan $\mathrm{N}$ total. Hasilnya dapat dilihat pada Gambar 4.

Proses yang dilakukan selama waktu 6 jam menghasilkan total $\mathrm{N}$ 3,7 ppm; 8 jam sebanyak 6,7 ppm; dan 20 jam menghasilkan $5,8 \mathrm{ppm}$. Pada kurva terlihat kandungan $\mathrm{N}$ total menurun pada HPG-amina yang dihasilkan dengan lama proses 20 jam. Hal ini kemungkinan terjadi karena dengan waktu yang lama menjadikan proses aminasi berlanjut, yang merubah amina primer menjadi amina sekunder. Dari analisa kandungan amina untuk HPG yang diaminasi dengan katalis $\mathrm{Ni}$ pada suhu $100{ }^{\circ} \mathrm{C}$ selama 8 jam diketahui sebesar 3,4 ppm dari $6,7 \mathrm{ppm}$ total $\mathrm{N}$. Hal ini menunjukkan bahwa ada sebanyak 3,3 ppm merupakan amonia bebas.

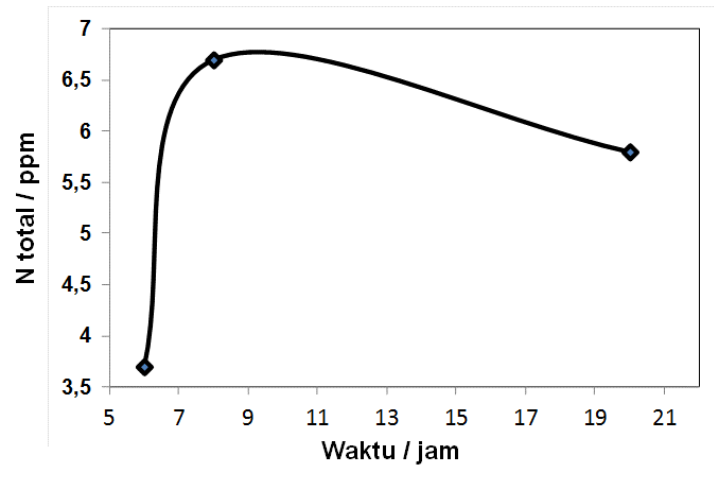

Gambar 4. Kurva hubungan lama proses dengan $\mathrm{N}$ total dalam HPG-amina

\section{KESIMPULAN}

Aminasi

HPG-amina dengan menggunakan gas amonia merupakan proses yang dimungkinkan untuk diperbesar menjadi skala industri serta lebih ramah lingkungan. Katalis berperan penting pada proses aminasi dimana tanpa katalis, tidak dapat merubah gugus hidroksi menjadi gugus amina.
Penggunaan katalis $\mathrm{Fe}$ sudah menghasilkan gugus amina, namun masih ada gugus karbonil $\mathrm{C}=\mathrm{O}$ yang belum teraminasi. Penggunaan katalis $\mathrm{Ni}$ menghasilkan HPG-amina dengan gugus amina primer $-\mathrm{CONH}_{2}$ dan amina sekunder R-NH. Suhu yang tinggi yaitu lebih dari $100{ }^{\circ} \mathrm{C}$ menjadikan produk HPG-amina berwarna lebih gelap dan keruh. Proses yang dilakukan lebih dari 8 jam menurunkan kandungan gugus amina yang terikat pada $H P$. Dalam penelitian ini HPG-amina yang diproses pada suhu $100{ }^{\circ} \mathrm{C}$, waktu 8 jam dengan penambahan katalis $\mathrm{Ni}$ menghasilkan total $\mathrm{N}$ sebanyak 6,7 ppm dan kandungan amina sebanyak 3,4 ppm.

\section{UCAPAN TERIMA KASIH}

Terima kasih penulis sampaikan kepada Kepala BBKK yang sudah menfasilitasi pelaksanaan penelitian ini. Terima kasih juga kepada rekan-rekan yang sudah membantu memodifikasi reaktor dan analisa kandungan amina sehingga selesainya penelitian ini.

\section{DAFTAR PUSTAKA}

Bähn, S., S. Imm, L. Neubert, M. Zhang, H. Neumann, dan M. Beller. 2011. "The Catalytic Amination of Alcohols." ChemCatChem 3 (12): 1853-64. doi:10.1002/cctc.201100255.

Gao, C., dan D. Yan. 2004. "Hyperbranched Polymers: From Synthesis to Applications." Progress in Polymer Science 29 (3): 183275. doi:10.1016/j.progpolymsci.2003.12.002.

Gomez, S., J.A. Peters, dan T. Maschmeyer. 2002. "The Reductive Amination of Aldehydes and Ketones and the Hydrogenation of Nitriles: Mechanistic Aspects and Selectivity Control." Advanced Synthesis and Catalysis 334 (10): 103757.

https://www.thevespiary.org/rhodium/Rhodi um/hive/hiveboard/picproxie_docs/000531 624-

AdvancedSynthesisAndCatalysis_Vol_344 Issue_10_p_1.pdf.

Griffin, J., J. Atherton, dan M.I. Page. 2013. "The Ammonolysis of Esters in Liquid Ammonia." Journal of Physical Organic Chemistry 26 (12): 1032-37. doi:10.1002/poc.3148.

Hajji, C., dan R. Haag. 2006. "Hyperbranched Polymers as Platforms for Catalysts." In Dendrimer Catalysis, 20:149-76. Berlin/Heidelberg: Springer-Verlag. doi:10.1007/3418 035.

Hellmund, M., K. Achazi, F. Neumann, Bala N. S. Thota, Nan Ma, dan R. Haag. 2015. "Systematic Adjustment of Charge Densities and Size of Polyglycerol Amines 
Reduces Cytotoxic Effects and Enhances Cellular Uptake." Biomaterials Science 3 (11). Royal Society of Chemistry: 1459-65. doi:10.1039/C5BM00187K.

Hollmann, D. 2008. "New Applications of the Borrowing Hydrogen MetthodologySelective Synthesis of Amines and Mechanistic Studies." Thesis. Universität Rostock.

https://www.researchgate.net/profile/Dirk Hollmann/publication/268419509_NEW_A PPLICATIONS_OF_THE_BORRŌWING_ HYDROGEN_METHODOLOGY_SELECTIVE_SYNTHESIS_OF_AMINES AND_MECHANISTIC_STUDIES/links/5547 18370 cf24107d3980fcb.pdf.

Khatri, R.A., S.S. Chuang, Y. Soong, dan M. Gray. 2006. "Thermal and Chemical Stability of Regenerable Solid Amine Sorbent for CO2 Capture." Energy \& Fuels 20 (4): 1514-20.

Likhar, P.R., R. Arundhathi, M.L. Kantam, dan P.S. Prathima. 2009. "Amination of Alcohols Catalyzed by Copper-Aluminium Hydrotalcite: A Green Synthesis of Amines." European Journal of Organic Chemistry 2009 (31): 5383-89. doi:10.1002/ejoc.200900628.

Pan, Hui-Jie, Teng Wei Ng, dan Yu Zhao. 2015. "Iron-Catalyzed Amination of Alcohols Assisted by Lewis Acid." Chemical Communications 51 (59): 11907-10.
doi:10.1039/C5CC03399C.

Rahmi, D., R. Yunilawati, dan A. Riyanto. 2016. "Sintesis Katalis Logam Berpenyangga Dendrimer Poligliserol Berbasis Turunan Kelapa Sawit." Jurnal Kimia Dan Kemasan 38 (2): 61-68.

Rahmi, D., R. Yunilawati, A. Riyanto, dan C. Nuraeni. 2017. "Karakteristik Mineral Lokal Sebagai Katalis Pada Sintesis Poligliserol Banyak Cabang (Hyperbranched Polyglicerol)." Jurnal Kimia Dan Kemasan 39 (2): 39-46. http://ejournal.kemenperin.go.id/jkk/article/v iew/3347.

Salazar, R., L. Fomina, dan S. Fomine. 2001. "Functionalized Polyglycidol-CuClComplexes as Catalysts in the Oxidative Coupling Reaction of Terminal Acetylenes." Polymer Bulletin 47 (2): 151-58. doi:10.1007/s002890170006.

Santoro, F., R. Psaro, N. Ravasio, dan F. Zaccheria. 2012. "Reductive Amination of Ketones or Amination of Alcohols over Heterogeneous Cu Catalysts: Matching the Catalyst Support with the N-Alkylating Agent." ChemCatChem 4 (9): 1249-54. doi:10.1002/cctc.201200213.

Seiler, M. 2006. "Hyperbranched Polymers: Phase Behavior and New Applications in the Field of Chemical Engineering." Fluid Phase Equilibria 241 (1-2): 155-74. doi:10.1016/j.fluid.2005.12.042. 